\title{
Perancangan Sistem Informasi Gudang Barang Jadi di PT Remaja ROSDAKARYA
}

\author{
${ }^{1}$ Ahmad Arif Nurrahman, ${ }^{2}$ Otong Rukmana. ${ }^{3}$ Indra Ahmad Fauzi \\ ${ }^{1,2,3}$ Program Studi Teknik Industri, Fakultas Teknik, Universitas Islam Bandung \\ Email: 'arif.nurrahman@unisba.com, 2otongrukmana@yahoo.com, ${ }^{3}$ indraahmadfauzi@gmail.com
}

\begin{abstract}
The development of information technology causes the need for an information system is needed in the workplace. Information systems can be used as a support in managerial decision making and operational support work. PT Remaja Rosdakarya is a company engaged in the field of printing. Problems often faced by the company that is often the number of incompatibilities between data dibuku and actual numbers, the data is stored only dibuku raises the risk of data loss. Therefore it will be done information system design of finished goods warehouse that can assist company in managing warehouse of finished goods.The approach taken in the development of information systems is Framework for the Application of Systems Thinking (FAST). Functional requirements required system that the system can enter the data entry goods, calculate the stock, store data items dikirmkan, and print mail delivery. In designing a warehouse system, using a MySQL database with XAMPP tools in designing warehouse databases and Adobe Dreamweaver in designing the display of sales information systems. With the design of this system, is expected to assist companies in managing data warehouse.
\end{abstract}

Keywords : Framework for the Application of Systems Thinking (FAST), PIECES, MySQL Database.

\begin{abstract}
Abstrak. Perkembangan teknologi informasi menyebabkan kebutuhan akan sebuah sistem informasi sangat dibutuhkan dalam dunia kerja. Sistem informasi dapat digunakan sebagai pendukung dalam pengambilan keputusan manajerial dan pendukung operasional pekerjaan. PT Remaja Rosdakarya merupakan perusahaan yang bergerak pada bidang percetakan. Permasalahan yang sering dihadapi oleh perusahaan yaitu sering terjadi ketidak sesuaian jumlah antar data dibuku dan jumlah yang sebenarnya, data disimpan hanya dibuku sehingga menimbulkan resiko kehilangan data. Oleh karena itu akan dilakukan perancangan sistem informasi gudang barang jadi yang dapat membantu perusahaan dalam mengelola gudang barang jadi. Pendekatan yang dilakukan dalam pengembangan sistem informasi yaitu metode Framework for the Application of Systems Thinking (FAST). Kebutuhan fungsional yang dibutuhkan sistem yaitu sistem dapat memasukan data barang masuk, menghitung stok, menyimpan data barang yang dikirmkan, dan mencetak surat jalan pengiriman. Dalam melakukan perancangan sistem gudang, menggunakan database MySQL dengan alat bantu XAMPP dalam merancang database gudang dan Adobe Dreamweaver dalam merancang tampilan sistem informasi penjualan. Dengan dirancangnya sistem ini, diharapkan dapat membantu perusahaan dalam mengelola data gudang.
\end{abstract}

Kata kunci : Framework for the Application of Systems Thinking (FAST), PIECES, Database MySQL.

\section{Pendahuluan}

Seiring dengan

perkembangan teknologi, kebutuhan akan sebuah sistem informasi sangat dibutuhkan dalam dunia kerja. Manfaat sistem informasi adalah sebagai pendukung dalam 
pengambilan keputusan manajerial dan pendukung operasional pekerjaan. Sistem informasi merupakan komponen yang saling bekerja sama untuk mengumpulkan, mengelolah, menghitung, menyimpan, dan menyebarkan informasi untuk mendukung menentukan keputusan, koordinasi, pengendalian, analisis masalah dan visualisasi dalam sebuah organisasi (Laudon dan Laudon, 2010).

Sistem informasi yang baik adalah sebuah sistem informasi yang mampu bekerja secara akurat, efektif, dan edisien. Sebuah sistem informasi dapat disajikan dengan sistem terkomputerisasi, yaitu pengolahan data yang semula dilakukan secara manual akan diolah dan disajikan menjadi data elektronik. Sistem komputerisasi ini mampu mempermudah pengolahan data, memperkecil kesalahan pengolahan data, dan mempercepat proses kinerja.

PT Remaja Rosdakarya adalah perusahaan yang bergerak di bidang percetkan yang beraa di Jl. Cimahi -Padalarang No. 31 Kab. Bandung Barat. Beberapa produk yang dihasilkan ialah buku SD SMP SMA/SMK, Ilmu Pengetahuan, dan Majalah. Dalam melakukan kegiatan pada gudang barang jadi masih dilakukan secara konvensional seperti dalam penginputan data barang masuk, data barang keluar, pembuatan laporan perbulan, dan mencetak surat jalan untuk pengiriman barang ke konsumen.

Permasalahan yang sering dihadapi ialah perbedaan data di buku catatan dengan jumlah real di gudang, terjadi penumpukan buku catatan data gudang barang jadi, lamanya pembuatan laporan perbulan, dan membutuhkan waktu lama saat dilakukan stock opname. Untuk mengatasi permasalahan tersebut PT Remaja Rosdakarya membutuhkan sistem informasi gudang barang jadi agar mempermudah proses penginputan data, mempercepat dan mempermudah stock opname, dapat mencetak surat jalan pengiriman barang ke konsumen.

Perancangan sistem informasi pergudangan dapat dilakukan dengan beberapa bahasa pemograman, seperti penelitian yang dilakukan oleh Boegi Sukamdana (2011) "Perancangan Sistem Informasi Inventory Berbasis Web Pada PT Citra Gemilang Prima, dan Reza Abadi Permana (2012) yang berjudul "Aplikasi Persediaan Barang Berbasis Web (Studi Kasus: Koperasi Pegawai Republik Indonesia)". Maka usulan dari peneliti ialah "Perancangan Sistem Informasi Gudang Barang Jadi (GBJ) Berbasis Desktop (Studi Kasus: PT Remaja Rosdakarya).

\section{Metode Penelitian}

Metode yang digunakan dalam perancangan sistem informasi yaitu metode Framework for the Application of System Thinking (FAST), dengan menggunakan Strategi Pengembangan Model Driven. Adapun tahapan metode FAST dapat dilihat pada Gambar 1.

Tahap 1 - Definisi Lingkup (Scope Definition)

Menentukan batasan dari pengembangan sistem dengan melakukan identifikasi terhadap masalah, inisiatif dan tujuan. 
Terdapat dua tujuan dari tahap ruang lingkup, yaitu menjawab pertanyaan apakah permasalahan ini cukup bernilai dan menetapkan ukuran, visi, kendala atau batasan apapun, yang diperlukan, dan juga anggaran serta jadwal dari proyek.

Tahap 2 - Analisis Masalah (Problem Analysis)

Analisa masalah merupakan tahap mempelajari sistem yang sudah ada dan menganalisa temuan-temuan agar dapat menemukan pemahaman yang lebih mendalam atas masalah yang memicu adanya proyek ini.

Tahap 3 - Analisis Persyaratan (Requirement Analysis)

Analisa kebutuhan merupakan tahap yang mendefinisikan dan memprioritaskan kebutuhan bisnis. Dengan kata lain memahami pengguna untuk mengetahui apa yang dibutuhkan atau inginkan dari sistem baru, dengan menghindari pembahasan tentang teknologi atau teknis pelaksanaan.

Ini mungkin merupakan tahap terpenting pengembangan sistem karena kesalahan dan kelalaian dari hasil analisis ini mengakibatkan ketidakpuasan pengguna dengan sistem final dan modifikasi yang mahal.

Tahap 4 - Perancangan Secara

Logika (Logical Design)

Pada tahap logical design adalah menerjemahkan kebutuhan bisnis ke dalam model sistem. Istilah logical design diartikan sebagai teknologi independen

Analisis pada dimana makna gambar menggambarkan sistem independen dari setiap kemungkinan solusi teknis, kebutuhan model bisnis yang diinginkan harus dipenuhi oleh solusi teknis yang ingin dipertimbangkan.

Tahap 5 - Analisis Keputusan (Decision Analysis)

Mengingat kebutuhan bisnis dan logical system models, biasanya banyak alternatif untuk merancang sebuah sistem informasi baru untuk memenuhi kebutuhan tersebut. Tujuan dari tahap ini adalah untuk mengidentifikasi pilihan solusi teknis, menganalisis solusi atas kelayakan dari pilihan tersebut, dan merekomendasikan pilihan sistem yang akan dirancang.

Tahap $6-$ Perancangan

Sistem Fisik (Physical Design and Integration)

Setelah solusi dipilih oleh managemen, langkah selanjutnya adalah melakukan transformasi dari kebutuhan bisnis dalam bentuk spesifikasi fisik yang akan menjadi panduan desain sistem.

Tahap 7 - Pembangunan dan Pengujian (Construction and Testing)

Tujuan dari tahap ini adalah untuk melakukan pengujian atas sistem yang telah dikembangkan untuk mengetahui tingkat penerimaan terhadap bisnis proses maupun pengguna sistem.

Tahap 8 - Pemasangan dan Penyampaian (Installation and Delivery)

Kegiatan ini adalah proses pemasangan perangkat lunak dan keras, sosialisasi dan pembuatan dokumentasi. 


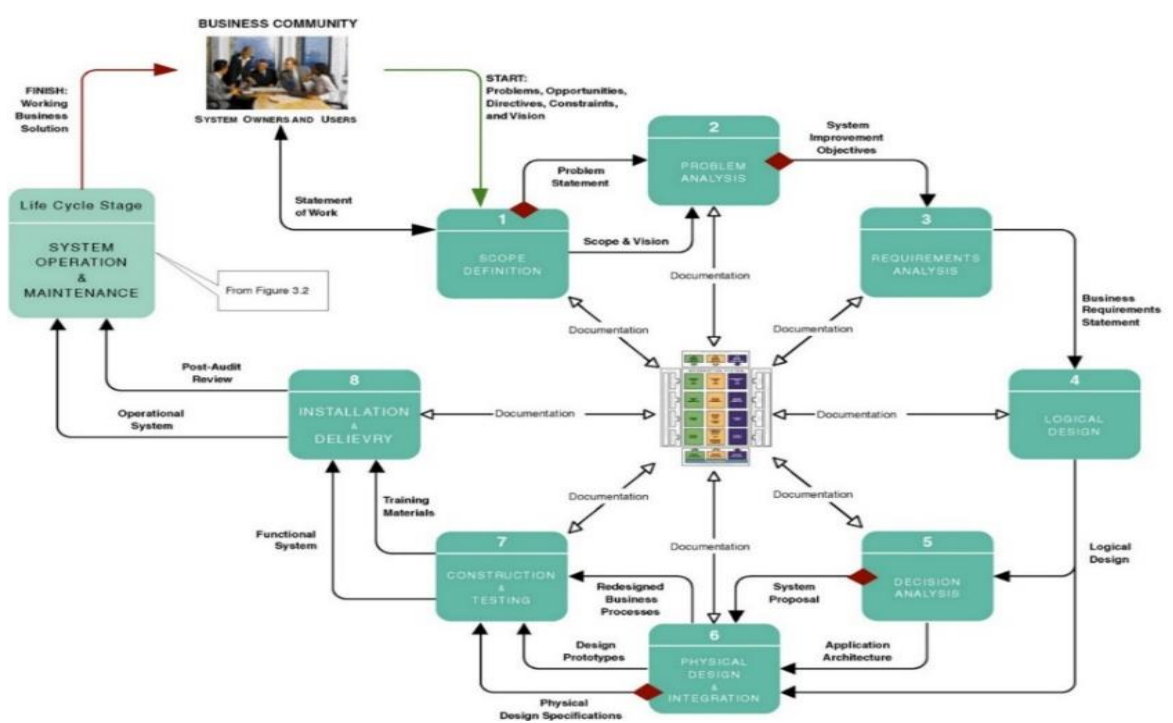

Sumber: Bentley \& Whitten (2007)

Gambar 1. Tahapan Metodologi FAST

UML (Unified Modeling Language) adalah salah standar bahasa yang banyak digunakan di dunia industri untuk mendefinisikan requirement, membuat analisis \& desain, serta menggambarkan arsitektur dalam pemrograman berorientasi objek. (Rosa A. S dan M.Shalahuddin, 2014).

\section{Hasil dan Pembahasan}

Permasalahan yang terjadi sekarang yaitu belum adanya sistem informasi yang dapat membantu aktivitas gudang barang jadi. Maka dari itu, sistem informasi penjualan memiliki kebutuhan sebagai berikut :

1. Sistem dapat melakukan login dan logout

2. Sistem dapat melakukan input data barang masuk
3. Sistem dapat melakukan penjumlahan data tersedia secara otomatis

4. Sistem dapat melakukan perekapan data barang terkirim

5. Sistem dapat membuat nota pengiriman barang

6. Sistem dapat melakukan pencarian data

7. Sistem dapat mencetak laporan perbulan.

\section{Pemodelan Komunikasi Sistem} Menggunakan Use -Case

\section{Diagram}

Model komunikasi sistem dimodelkan dengan menggunakan use -case diagram, pemodelan tersebut terdiri dari beberapa komponen, yaitu use -case, actor, dan hubungan. Use -case diagram tersebut dapat dilihat pada Gambar 2. 


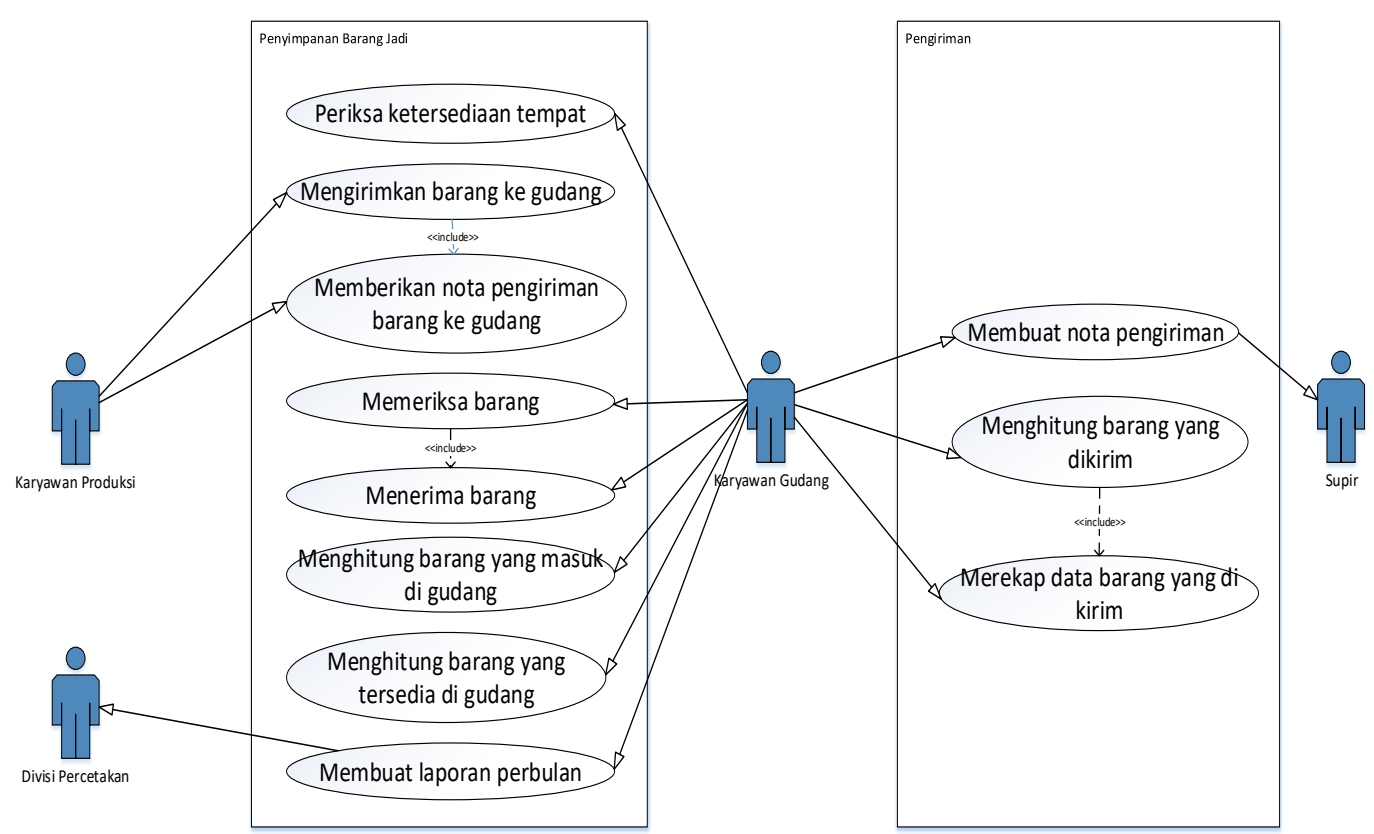

Gambar 2. Use -Case Diagram

\section{Pemodelan Data Menggunakan Class Diagran}

Diagram kelas atau class diagram menggambarkan struktur sistem dari segi pendefinisian kelaskelas yang akan dibuat untuk membangun sistem. Kelas memiliki apa yang disebut atribut dan metode atau operasi. (Rosa A. S dan M.Salahhudin, 2014). Adapun class diagram tersebut dapat dilihat pada Gambar 3.

\section{Data Barang Masuk \\ - Kode Barang Masuk \\ - Tgl Masuk Barang \\ - Kode Barang \\ - Nama Barange \\ Judu Barang \\ Nama Penulis \\ Jumlah Eksemplar \\ -Simpan}

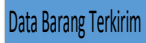

Kode Penginiman Barang

- Tg Keluar Barang

- Kode Barang

- Nama Barang

Judul Barang

- Nama Penulis

-Jumlah Eksemplar

- Edit

- Hapus
Gambar 3. Class Diagram
Pemodelan

Menggunakan

Diagram dan

Diagram

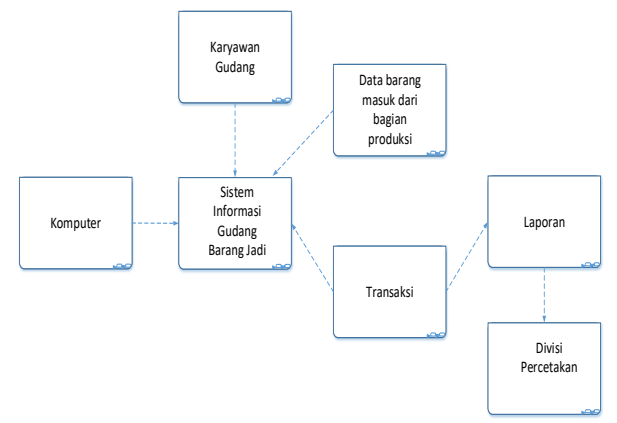

Gambar 4. Componant Diagram

Berdasarkan Gambar 4, maka dapat dijelaskan component diagram tersebut sebagai berikut :

1. Aplikasi website dapat diakses melalui perangkat komputer

2. Karyawan gudang melakukan kelola user untuk penggunaan web

3. Data barang masuk dari produksi digunakan untuk akses transaksi. 
4. Apabila data barang masuk dan transaksi diproses maka akan menentukan laporan. Deployment diagram menunjukan konfigurasi komponen dalam proses ekskusi aplikasi. Deployment diagram menggambarkan detail bagaimana komponen di-deploy dalam infrastruktur sistem, dimana komponen akan terletak (pada mesin, server atau piranti keras), bagaimana kemampuan jaringan pada lokasi tersebut, spesifikasi server dan halhal lain yang bersifat fiskal. (Rosa A. $S$ dan M.Shalahuddin, 2014). Adapun deployment diagram tersebut dapat dilihat pada Gambar 5.

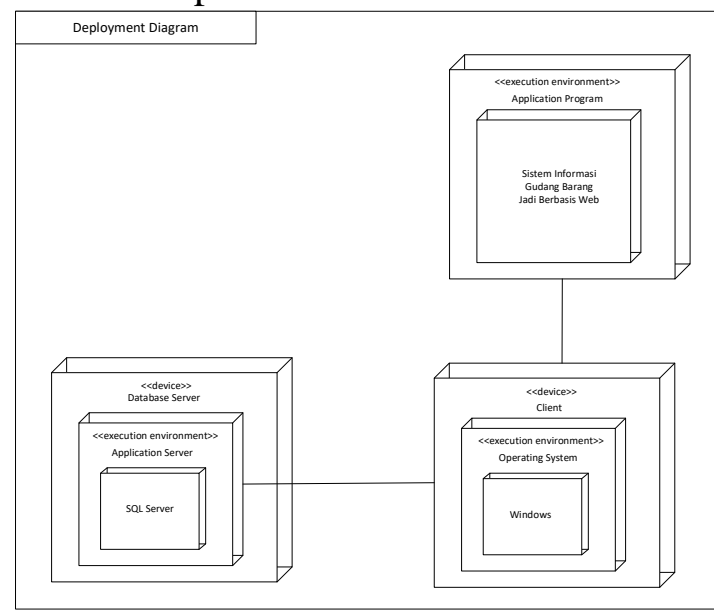

Gambar 5. Deployment Diagram

\section{Perancangan Interface (Package Diagram)}

Diagram ini untuk mengatur pengorganisasian diagram class yang kompleks, dapat dilakukan pengelompokan kelas -kelas berupa package (paket -paket). Diagram ini merupakan kumpulan elemen elemen logika UML, adapun package diagram tersebut dapat dilihat pada Gambar 6.

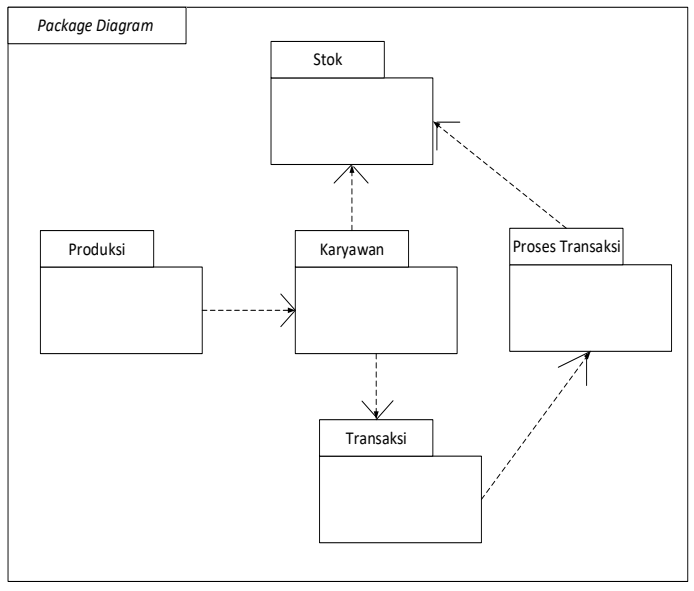

Gambar 6. Package Diagram

\section{Antarmuka}

Antarmuka sistem merupakan tampilan dari sistem yang telah dibuat berdasarkan rancangan sistem. Adapun gambaran antarmuka dashboard sistem dapat dilihat pada Gambar

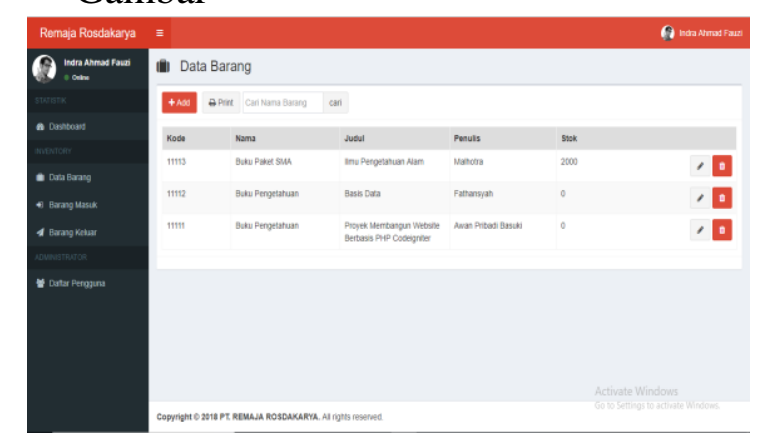

Gambar 7. Rancangan Antarmuka

\section{Kesimpulan}

Berdasarkan hasil penelitian penulis di PT Remaja Rosdakarya, maka terdapat beberapa hal yang dapat disimpulkan ialah sebagai berikut:

1. Proses di gudang barang jadi saat ini yaitu masih menggunakan sistem konvensional yang dimulai dari proses barang masuk ke gudang dari bagian produksi, dokumentasi barang masuk, 
dokumentasi barang yang tersedia, dan dokumen barang yang terkirim. Hal tersebut menyebabkan terjadinya beberapa permasalahan yang saat ini dihadapi, diantaranya semua proses dokumentasi hanya menggunakan buku, data jumlah barang yang masuk ke gudang tidak sesuai dengan data yang tertulis dibuku, dokumentasi hanya dibuku saja, data masa lampau hanya di simpan dibuku lalu disimpan di lemari.

2. Sistem yang dibutuhkan oleh perusahaan saat ini yaitu sistem yang dapat mempermudah dalam dokumentasi, menyediakan database yang bisa menyimpan semua data gudang barang jadi, kemudian dapat memperlihatkan grafik gudang garang jadi sehingga dapat diketahui peningkatan atau penurunan proses produksi dari waktu ke waktu.

3. Perancangan sistem informasi Gudang Barang Jadi menggunakan pendekatan metode FAST (Framework for the Application of System Thinking) yang dimulai dari definisi lingkup, analisis masalah, analisis kebutuhan. Perancangan model proses logika, dan perancangan model data fisik dengan menggunakan pemodelan UML (Unified Modeling Language) yang didalamnya terdapat use diagram, activity diagram, sequence diagram, class diagram, component

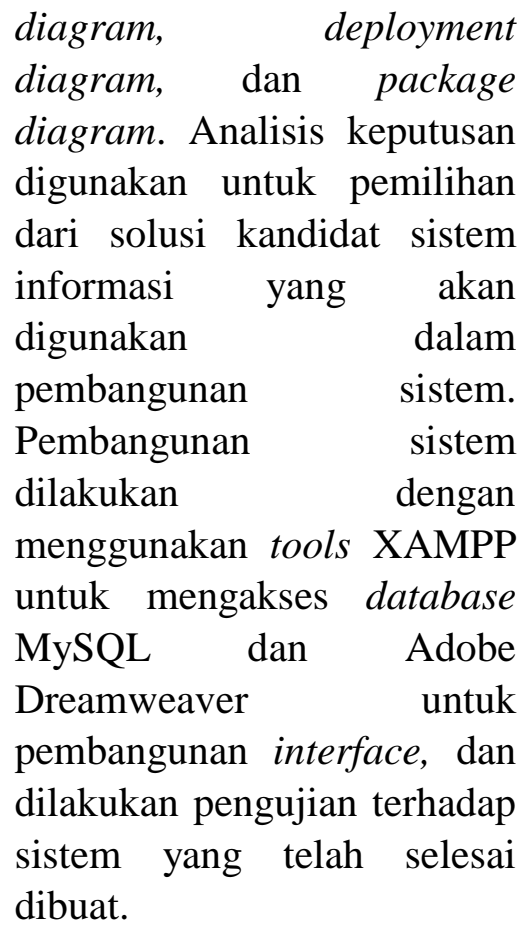

\section{Saran}

Adapun beberapa saran yang dapat diajukan berdasarkan dari hasil penelitian yang terlah dilakukan ialah

1. Diperlukan adanya pelatihan terhadap kepala bagian percetakan, dan karyawan bagian gudang barang jadi yang akan menggunakan sistem informasi gudang barang jadi tersebut agar sistem yang telah dirancang dapat dipahami.

2. Penelitian ini dapat dikembangkan kembali agar bisa memperbaiki kekurangan sistem yang ada dan menjadi lebih baik lagi dari sebelumnya.

\section{Daftar Pustaka}

Arel Riedsa Adiguna, M. C. 2018. Analisis dan Perancangan Sistem 
Informasi Manajemen Gudang pada PT Mitra Pinasthika Mulia Surabaya. Jurnal Pengembangan Teknologi Informasi dan Ilmu Komputer Vol. 2, No. 2,Februari 2018, hlm 612-621.

Boegi, S. 2011. Perancangan SIstem Informasi Inventory Berbasis Web Pada PT Citra Gemilang Prima. Jurnal SIstem Informasi Vol. 1, No. 1, 2011, hlm. 59 -81.
Permana, R. F. 2012. Aplikasi Persediaan Barang Berbasis Web (Studi Kasus: Koperasi Pegawai Republik Indonesia). Jurnal Perancangan Sistem Informasi Vol.2, No.2.

Rosa A. S Dan M Shalahudin, R. A. 2014. Rekayasa Prangkat Lunak. Sistem Informasi.

Whitten J.L. dan Bently, L. D. 2007. System Analysis And Design Methods. 